\title{
Compact yarn as a replacement of doubled yarn in apparel fabric-an analytical snap
}

\begin{abstract}
Regularity is the prime consideration for the yarn used for apparel fabric as it imparts not only desired better appearance but also additionally improvement in mechanical properties as well as aesthetic appeal. That's why doubled yarn has enjoyed a dominating position in this sector since long although costly due to its longer production route. Contrariwise in past few years regular and low hairy compact yarn has created a landmark for the singles in the commercial market. This fabulous performance is the outcome of better fiber integration caused by fiber condensation done just before twisting. The present experiment was thereby conducted to analyze its caliber as a double yarn replacement in the apparel sector.
\end{abstract}

Keywords: compact yarn, apparel fabric, analytical snap, doubled yarn
Volume I Issue 5 - 2017

\author{
Tasnim N Shaikh', Rainish Radadiya, ${ }^{2}$ Akshar \\ Rawal ${ }^{3}$
}

Department of Textile Engineering, The Maharaja Sayajirao University of Baroda, Indias

Correspondence: Rainish Radadiya, Department of Textile Engineering, Assistant Professor of Technology \& Engineering, The Maharaja Sayajirao University of Baroda, India, Tel 9998473193, Email r.v.radadiya-ted@msubaroda.ac.in

Received: March 27, 2017 | Published: May 08, 2017

\section{Introduction}

The spirit of spinning technologists involved in apparel industry is always focused round higher productivity and wearer comfort combined with an adequate quality. For several years, doubled yarns are used invariably for the production of suiting, shirting and dress materials irrespective of their type; knitted or woven. ${ }^{1}$ This domination of two folded yarns over singles is credited for their excellent properties especially good appearance although achieved on sacrificing economy to some extent.

The spinning sector witnessed compact spinning as a striking improvement in the machinery design which has carved a niche and led to significant improvements in yarn regularity especially hairiness at much more an economical rate. ${ }^{2}$ It has thereby rapidly established a strong position in the commercial market especially in the areas where normal single yarns quality flops due to higher irregularities and hairiness. Its quality is said to be much more competent with doubled yarn as compared to its single yarn group fellows. So it becomes interesting to investigate comparative status of fabrics produced identically by using conventional doubled and compact yarns for apparel purpose in terms of quality and cost saving capabilities. Comfort of the apparel fabrics relates to its moisture transportation efficacy, and it is also an important criterion to be talked about especially when competing yarns compactness is not identical. ${ }^{3-5}$

\section{Experimental}

Effect of substitution of a doubled yarn with equivalent size single compact yarn on the quality and cost of fabric was verified.

\section{Material}

$100 \%$ cotton single compact yarn: doubled yarn pairs were used. Possible yarn sizes representing coarse, medium, fine and superfine groups and used in apparel sector either in woven or knitted form of fabrics were considered in pairs for the study, they are:

a. Woven fabric: $20^{s} \mathrm{~N}_{\mathrm{e}}-2 / 40^{\mathrm{s}} \mathrm{N}_{\mathrm{e}}, 40^{\mathrm{s}} \mathrm{N}_{\mathrm{e}}-2 / 80^{\mathrm{s}} \mathrm{N}_{\mathrm{e}}$ and $50^{\mathrm{s}} \mathrm{N}_{\mathrm{e}}$ $-2 / 100^{\mathrm{s}} \mathrm{N}_{\mathrm{e}}$

b. Knitted fabric: $30^{s} \mathrm{~N}_{e}-2 / 60^{s} \mathrm{~N}_{e}$ and $60^{s} \mathrm{~N}_{e}-2 / 120^{s} \mathrm{~N}_{\mathrm{e}}$.

\section{Methods}

Both the categories of yarns were woven on Tsudakoma ZAX9100 loom under identical conditions, by using same type of yarn (compact/doubled) as warp as well as weft. Plain weave, usually adopted in apparel fabrics irrespective of yarn size was used for the purpose. For knitting purpose Precision Fukuhara works; model 3.2 $\mathrm{S}$ latch needle weft wind circular knitting machine was used. Both the categories of fabrics were verified for quality parameters true for apparel fabric, viz; Constructional properties, mechanical properties, comfort associated properties and aesthetic properties by using standard test method after conditioning for 24 hours.

\section{Results and discussion}

Fabric parameters are discussed in four groups as per tested

\section{Constructional properties}

The measured values for structural parameters of both the categories of fabrics are summarized in Table 1 Grey fabric sett values were altered from the loom sett-values for all the categories due to length and width shrinkage undergone by the fabrics on the relaxation of weaving stresses. Invariably width shrinkage observed was higher owing to higher weft tension evolved during high speed air jet weaving for all the categories.

Compact yarns based fabrics have executed poor dimensional stability as compared to equivalent doubled, attributed mainly to their lower extensibility against higher weaving stresses. Extent of crimpiness introduced on weaving and proportionate change in linear density of compact yarns were not only higher but remarkably different for warp and weft, although plain weave was used and yarn type and size were kept same during weaving. Since rise in constituent yarns linear density is more for compact yarn woven fabrics, they have also executed higher GSM and thickness as compared to respective doubled yarns fabric.

The performance of apparel fabric should be judged in terms of cover factor (equation 1) rather than physical measures of GSM and thickness. ${ }^{6-9}$ 


$$
\mathrm{K}_{\mathrm{c}}=\mathrm{K}_{1}+\mathrm{K}_{2}-\frac{\mathrm{K}_{1} \mathrm{~K}_{2}}{28}
$$

Where, $\mathrm{K}_{1}$ and $\mathrm{K}_{2}$ are warp cover factor and weft cover factor calculated on the basis of respective yarn density $(n)$ and linear density in English count system $(\mathrm{N})$ as per following relationship:

$$
\mathrm{K}_{1}=\frac{\mathrm{n}_{1}}{\sqrt{\mathrm{N}_{1}}} \& \mathrm{~K}_{2}=\frac{\mathrm{n}_{2}}{\sqrt{\mathrm{N}_{2}}}
$$

Similarly for knitted pair cover factor was calculated as per equation 3

$$
\mathrm{K}_{\mathrm{c}}=\frac{\sqrt{\mathrm{N}_{\text {tex }}}}{1}
$$

Where $\mathrm{N}$ is yarn count in Tex and $\mathrm{l}$ is stitch length in $\mathrm{mm}$.

Results of cover factors are presented schematically in (Figure $1(\mathrm{~A}) \&(\mathrm{~B})$. Higher cover factor was gone on the account of bulkier compacts in both the categories of fabrics except for coarser $20^{\mathrm{s} *} 20^{\mathrm{s}}$ Vs. 2/40. Difference in the value was quite high for knitted as compared to woven. ${ }^{10-18}$

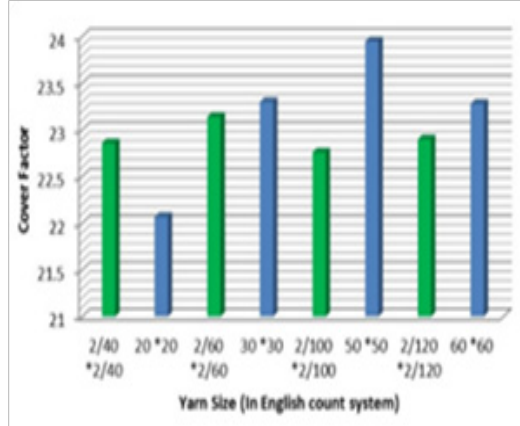

(A) Woven Fabric

Figure I Fabric Cover.

\section{Mechanical properties}

Apparel fabric should not necessarily possess higher strength but should be able to sustain various stresses during forthcoming production processes as well as end use application point.

Tensile properties: In the present study except constituent yarns all weaving conditions were kept constant for all the pairs. So the breaking force and elongation at break of the fabrics were mainly influenced by the tensile properties of the constituent yarns used as well as their Cloth Assistance Factor (CAF) ${ }^{13}$ Cloth Assistance Factor (CAF) was evaluated as per equation 4.

Cloth Assistance Factor $(\mathrm{CAF})=\frac{\text { Fabric strength per thread }}{\text { Yarn strength in bobbin }}$

Higher CAF value in warp direction was reported for the double yarn fabric for finer yarn but lower for coarser yarn category. However CAF value in weft direction was invariably high for compact yarn based fabrics irrespective of yarn count Figure 2. Higher CAF values are the outcome of preferable increase in yarn to yarn friction for the selected plain weave. This phenomenon can be well realized from the tensile strength plots where higher tensile strength values were found in the account of double yarn fabrics in both the directions Figure 2.

Abrasion resistance: It is an ability of constituent yarns to withstand repeated distortion and is the key factor in defining serviceability of the apparel fabric. Higher abrasion resistance irrespective of warp or weft direction and fabric structure (woven or knitted) has gone on the account of double yarn fabrics. This is due to comparatively stiffer constituents (two step twisting) incorporated in the fabric structure, resisted more against abrading agency under the applied pressure. ${ }^{19-22}$ However effect for knitted fabric and woven fabric with finer counts was not so prominent Figure 3.

\section{Pilling}

It represents undesirable measure for apparel fabric that is creation

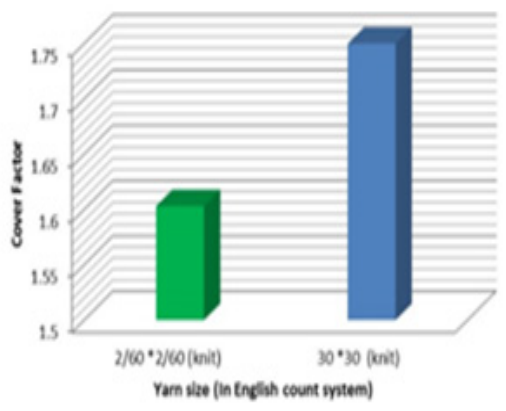

(B) Knitted Fabric

of hairiness and pills (small ball like structure of fibers) on the fabric surface when subjected to wearing agency. Parenthesis of better fiber integrated structures, rating of " 5 " that is, "No or very weak formation of pills" was attained by both the categories of fabrics irrespective of count range. One special note put up by expert was that although rating for coarse yarn pair (20s Ne and $2 / 40 \mathrm{~s} \mathrm{Ne}$ ) was same but extent of hairiness observed within the range was less for compact based fabric Figure 4.

\section{Comfort related properties:}

Physiological comfort is very basic and necessary property of the apparel fabric and important than the aesthetic properties when the garments are worn next to skin like inner garment and the wears of delicate use such as ladies and infant dress materials. List of comfort properties is long but usually considered for apparel are air permeability, bulk and, water management. ${ }^{23,24}$

Air permeability: Higher air permeability was gone customarily on the account of double yarn. This is mainly due to tightly packed structure of doubled yarns obtained on doubling of constituent finer single yarns by twist-on-twist method. Fabric composed of such yarns have more porousness and likely to show higher air permeability. ${ }^{25-27}$ Low cover factor Figure 1 observed for double yarn fabrics also substantiate this argument. However, difference observed was not profound for woven fabrics in all yarn size as that can be seen in case of knitted fabrics Figure 5.

\section{Bulk of the fabric}

It facilitates in defining comfort to the wearer especially for apparels due to ease of moisture vapour transaction. It is clear from the diagram Figure 5 that compact based fabrics have offered good competition to double yarn by showing almost identical bulk. But no doubt in case of knitted fabric double yarn fabric has ascertained higher bulk.

Moisture management: Capillary action or capillarity can be defined as the macroscopic motion or flow of a liquid under the influence 
of its own surface. Thereby it is utmost important for the garment next to the skin should absorb the sweat quickly and transport it to the outer surface of the garment. From the outer surface, sweat should be evaporated quickly to keep the body dry or cool. All these desired phenomena come under one technical term called "Moisture management" and given lot of priorities for textiles used in apparels. ${ }^{28}$

Test results of moisture management are plotted graphically for woven as well as knitted fabrics in Figure 6(A) and test sample views are shown in Figure 6(B). Knitted fabric made up of double yarns has shown prominence in moisture management not only on respective compact substitute but also on rest of the pairs in consideration. Contradictory to knitted structure in case of woven fabrics, compacts based fabrics have shown better moisture management. This must be attributed to comparatively softer yarns participated in tightly integrated woven fabric structure.
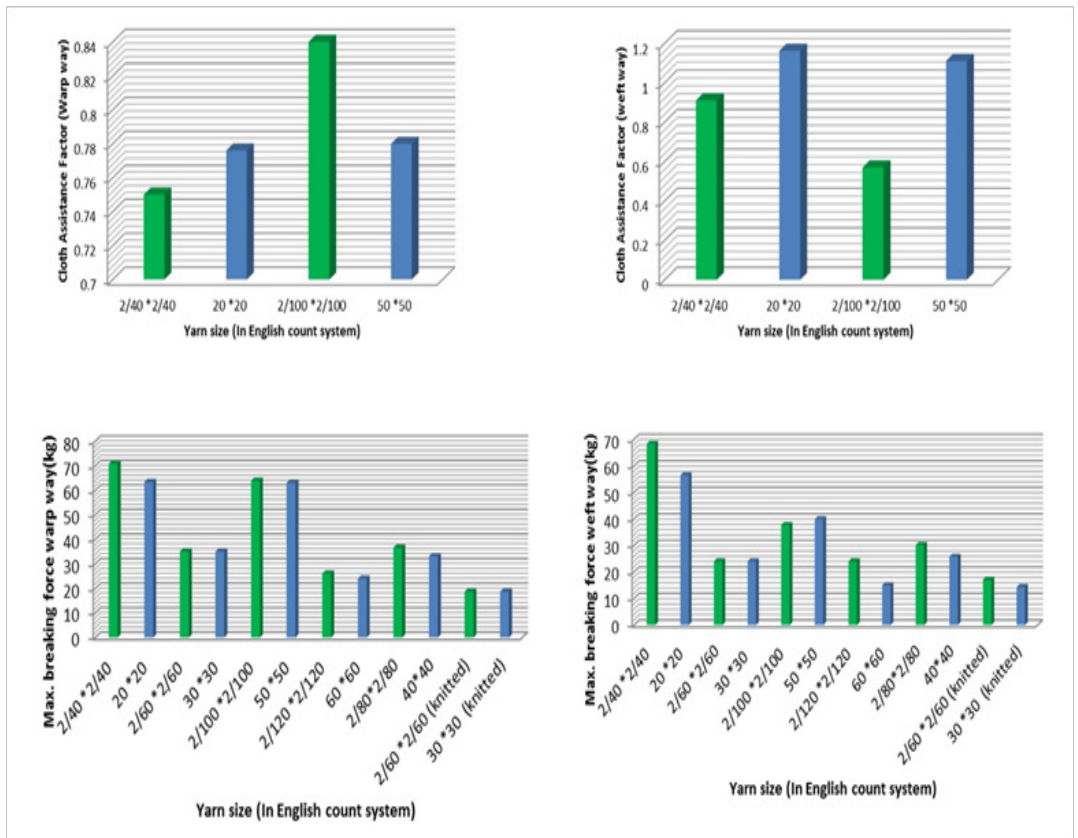

Figure 2 Fabric CAF value and Tensile value plots.
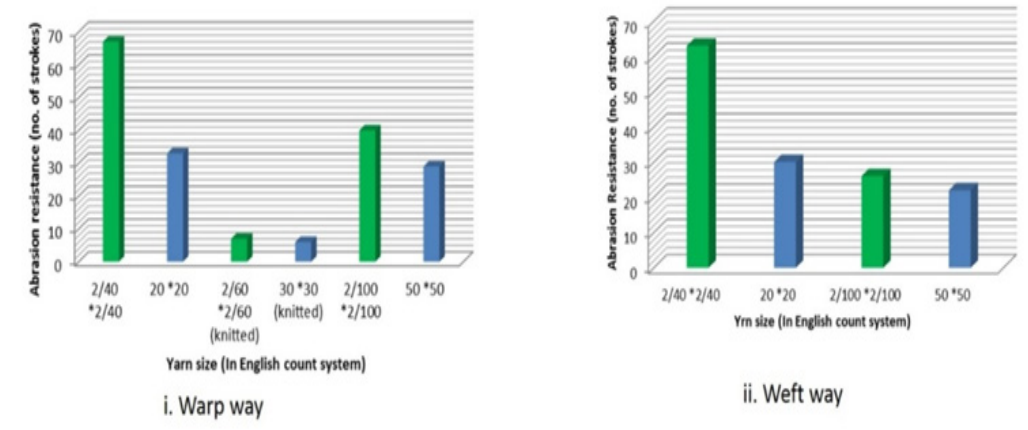

Figure 3 Abrasion resistance.

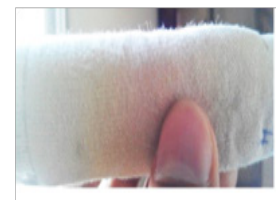

$2 / 40^{5} \mathrm{Ne}$

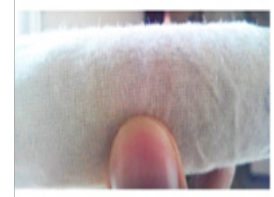

$20^{5} \mathrm{Ne}$

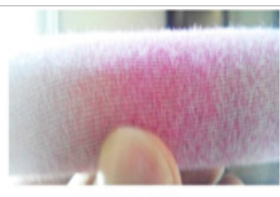

$2 / 60^{\mathrm{s}} \mathrm{Ne}$ (knit)

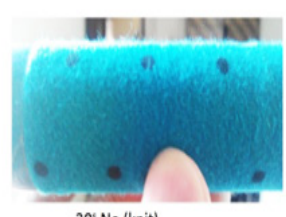

$30^{5} \mathrm{Ne}$ (knit)

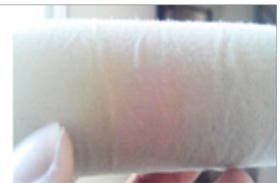

2/ $100^{\mathrm{N} N \mathrm{Ne}}$

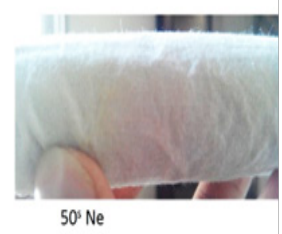

Figure 4 Fabric Pilling. 


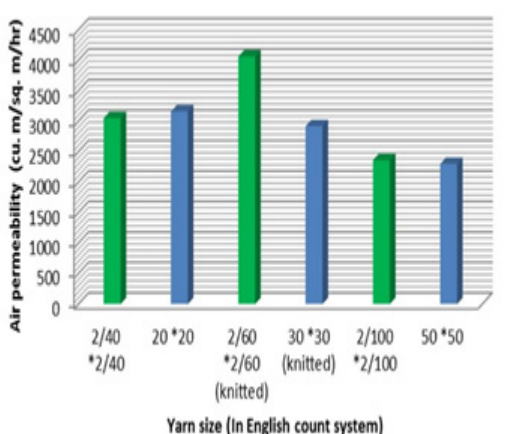

Figure 5 Fabric Air permeability \& Bulk.

\section{Aesthetical properties}

Beauty of any apparel fabric lies in how best it resumes graceful appearance and retains it for a long time on wearing and normally judged by its drape, stiffness and crease recovery values. ${ }^{29}$ Drape and stiffness are just like synonyms for fabric thereby their plots are given together in Figure 7. Unlike knitting and against the expectation softer compact yarns fabrics have executed higher stiffness and drape values in woven structure.

This may be attributed to the tightness of the weave; plain weave used more than the yarn stiffness. This argument gets the support from the test results observed for soft and comparatively loosely knitted

Table I Structural Parameters

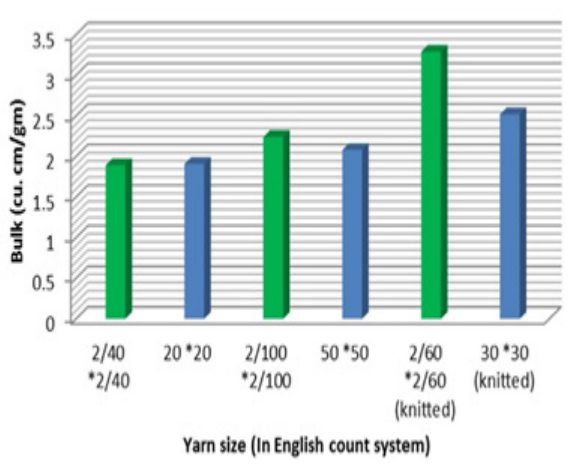

structure. Even basic theory of stiffness described by Booth \& Savile ${ }^{14}$ substantiate this argument, accordingly thicker fabric with higher weight per unit area Table 1 results in increased stiffness thereby executes higher bending length and thereby higher bending rigidity value. Further stiffer fabric resumes higher drape value.

Tightness of the weave and characteristics of constituents largely usually affect crease recovery behavior of the fabric. In the present study tightness of the weave has played determinant role and closely packed structure has executed better recovery from the deformation. That's why soft and bulky but tightly packed compact yarns fabric have shown better warp way crease recovery but lower recovery in weft direction Table 1.

\begin{tabular}{|c|c|c|c|c|c|c|c|c|c|c|}
\hline $\begin{array}{l}\text { Fabric } \\
\text { property }\end{array}$ & Compact & Double & Compact & Double & Compact & Double & Compact & Double & Compact & Double \\
\hline \multicolumn{11}{|c|}{ Linear density of constituent yarns } \\
\hline $\begin{array}{l}\text { Warp Count } \\
(\mathrm{Ne})\end{array}$ & 18.01 & 19.06 & 25.86 & 27.54 & 35.09 & 37.04 & 43.5 & 49.01 & 54.57 & 57.99 \\
\hline $\begin{array}{l}\text { Weft Count } \\
(\mathrm{Ne})\end{array}$ & 18.45 & 18.86 & 27.8 & $27.5 I$ & 36.71 & 37.11 & 48.69 & 48.61 & 56.01 & 58.12 \\
\hline \multicolumn{11}{|l|}{ Crimp (\%) } \\
\hline Warp & 11.2 & 7 & 16 & 9 & 14 & 8 & 14 & 6 & 12 & 6 \\
\hline Weft & 8 & 7.3 & 10 & 9 & 9 & 7 & 8 & 5 & 8 & 6 \\
\hline GSM & 201.9 & 187.4 & 150.4 & 134.2 & 132 & 129 & 123.5 & 106.9 & || $2.4 \mid$ & 108.9 \\
\hline $\begin{array}{l}\text { Fabric sett: } \\
\text { ends/cm x } \\
\text { picks } / \mathrm{cm}\end{array}$ & $70 * 58$ & $78 * 60$ & $67 * 58$ & $69 * 57$ & $74 * 63$ & $72 * 64$ & $130 * 100$ & $134 * 80$ & $135 * 108$ & $134 * 109$ \\
\hline $\begin{array}{l}\text { Thickness } \\
(\mathrm{mm})\end{array}$ & 0.382 & 0.312 & 0.442 & 0.38 & 0.3512 & 0.3422 & 0.258 & 0.24 & 0.2215 & 0.2188 \\
\hline \multirow[t]{2}{*}{$\begin{array}{l}\text { Dimensional } \\
\text { Stability }\end{array}$} & $-2.89 \%: \mathrm{L}$ & $-1.8 \%: L$ & $-2.8 \%: L$ & $-1.6 \%: \mathrm{L}$ & $-2.5 \%: L$ & $-1.5 \%: L$ & $-2.3 \%: \mathrm{L}$ & $-1.2 \%: L$ & $-2.0 \%: L$ & $-1.2 \%: \mathrm{L}$ \\
\hline & $-3.2 \%: \mathrm{W}$ & $-1.8 \%: W$ & $-3.1 \%: W$ & $-1.7 \%: W$ & $-3 \%: W$ & $-1.5 \%: \mathrm{W}$ & $-2.8 \%: \mathrm{W}$ & $\begin{array}{l}-1.24 \%: \\
W\end{array}$ & $-1.9 \%: W$ & $-1.2 \%: \mathrm{W}$ \\
\hline
\end{tabular}

\section{Fabric costing}

Based on the data availed from the industry involved in the business of shirting comparative average costing status for $50^{\mathrm{s}} \mathrm{Ne}$ compact yarn based fabric and $2 / 100^{s} \mathrm{Ne}$ double yarn fabrics is given in Table 2 .

According to technical discussion held, fabric costing is mainly influenced by yarn cost (approx. 55 to 65\%) and fabric manufacturing cost which differs mainly due to loom efficiency. Thereby for the grey fabrics woven under the identical condition, yarn cost mainly determines fabric cost and it is always higher for double yarn fabric (by $100 \mathrm{Rs} / \mathrm{m}$ in present case), the difference can be increased further on moving toward finer yarn size and vice versa.

The cost will be increased on finishing depending on the type of finish applied. There are two main techniques employed to apply the finish on the fabric: mechanical and chemical. Mechanical finish is cheaper compared to chemical finish, almost half, so fabric cost is 
accounted accordingly. If the fabric is to be printed then extra charge is applied depending on the print. This addition is done over and above dyeing or finishing cost as per the sequence of process followed. ${ }^{30-32}$ In case of knitted fabric for the same yarn size, the fabric made out of doubled yarn is $125 \mathrm{Rs} / \mathrm{m}$ (instead of $100 \mathrm{Rs} . / \mathrm{m}$ ) costlier than the fabric made from compact yarn.

Table 2 Fabric costing

\begin{tabular}{lll}
\hline Type of fabric & $\begin{array}{l}\mathbf{5 0 s} \text { Ne compact } \\
\text { yarn based fabric } \\
(\mathbf{R s} / \mathbf{m})\end{array}$ & $\begin{array}{l}\mathbf{2} / \mathbf{1 0 0 s} \text { Ne doubled } \\
\text { yarn based } \\
\text { fabric(Rs/m) }\end{array}$ \\
\hline Grey & 130 & 230 \\
Piece dyed & $130+20$ & $230+20$ \\
Finishing & $130+6$ to 50 & $230+6$ to 50 \\
Printing & $130+20+15$ to 30 & $230+20+15$ to 30 \\
\hline
\end{tabular}

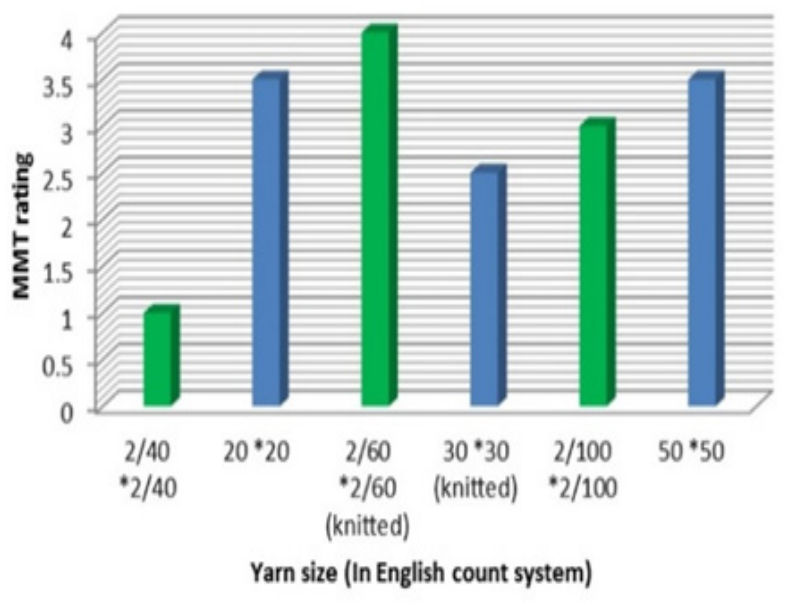

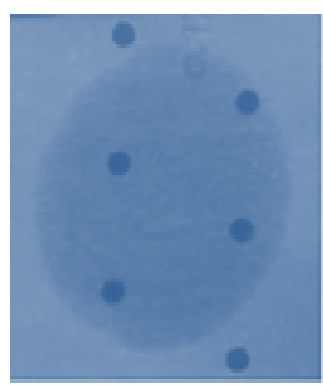

$30^{5}$ Ne Front

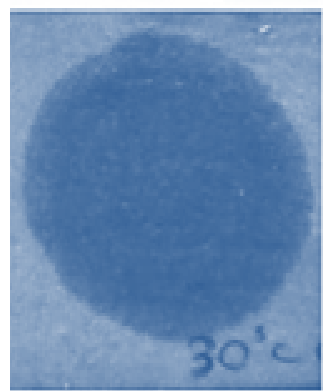

$30^{5} \mathrm{Ne}$ Back

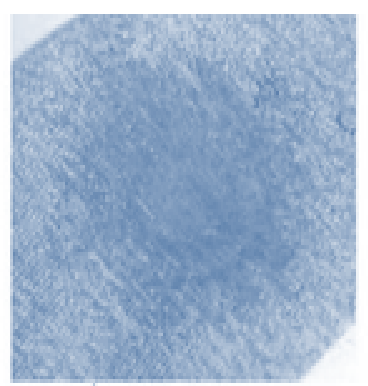

$2 / 60^{5}$ Ne Front

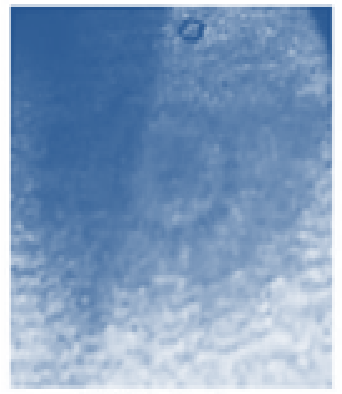

$2 / 60^{s} \mathrm{Ne} B \mathrm{Back}$
(A) Test results (B) Tested fabric views

Figure 6 Moisture Management.
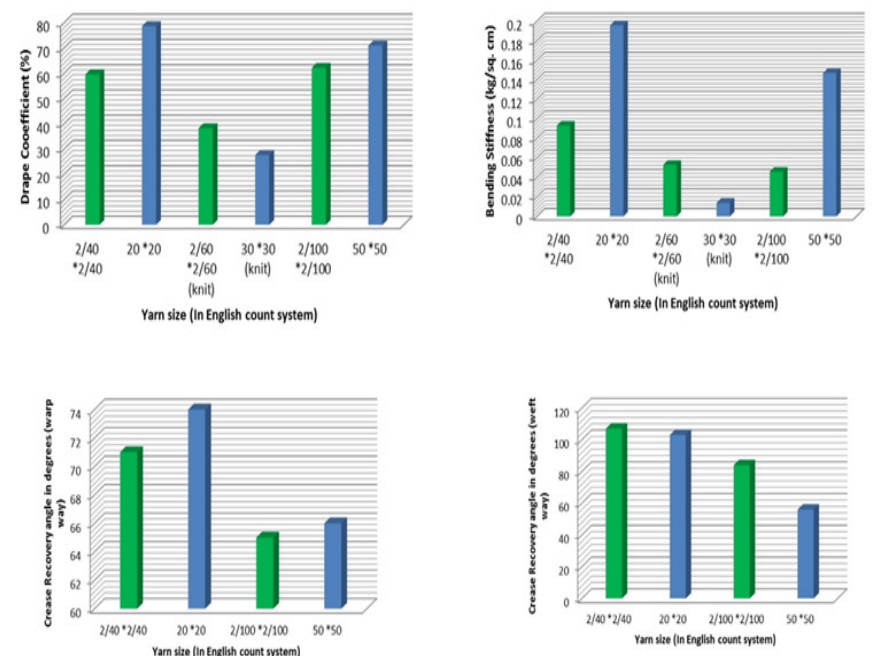

Figure 7 Fabric Drape and Stiffness.

\section{Conclusion}

The experiment was conducted to evaluate efficacy of appealingly regular and low cost compact singles as a replacement of commercially established but costlier doubled yarns in apparel fabric. Yarn size representing coarse to fine in pairs (doubled: compact) were chosen for the purpose and both the pairs of yarns were woven or knitted under identical condition for getting reliable ground of comparison.

Compact yarns based fabrics have executed poor dimensional stability and thereby higher crimpiness, thickness and GSM as compared to equivalent doubled, mainly due to their lower extensibility against higher weaving stresses. Increased crimpiness was resulted in better fabric cover for bulky compact yarn based fabrics in both the categories except for coarser yarn count.

Better mechanical properties in terms of tensile strength and abrasion resistance were observed for stronger and uniform double yarn fabrics irrespective of woven or knitted structure. Although performed equivalent to doubled fabrics in terms of pilling tendency, compact yarns fabric scored additional positive remark due to well integrated fibers in its structure which resulted in less degree of hairiness.

Comfort associated properties, viz; air permeability, bulk and moisture management, compact yarns woven fabrics have finished very close to competitor doubled and even scored superiority. However, contradicting to woven, doubled yarn knitted fabric was found better than its substituent compact in this regards.

Compact yarn based woven fabrics gave higher drape, stiffness and warp way crease recovery but lower for knitted one. However, better value in case of aesthetic properties is a relative measure and differs as per end user's requirements.

Low cost single compact yarn has proven domination over fabric production cost and shown better economy as per expectations in all fabric manufacturing to finishing stages. Difference observed in fabric cost was further higher in case of knitted fabrics.

Thus compact yarn has enough strength to replace doubled yarn in terms of quality and cost for apparel sector irrespective of type of fabric manufacturing system adopted about. 


\section{Acknowledgments}

None.

\section{Conflict of interest}

Author declares there is no conflict of interest in publishing the article.

\section{References}

1. Akaydin M. Characteristics of fabrics knitted with basic Knitting structures from combed ring and compact yarns. Indian J fiber \& Text Res. 2009;34:26-30.

2. Artzt P. Possibilities of improving the efficiency of compact spinning. Melliand Int. 2002;8(1):28-30.

3. Behera BK, Hari PK, Ghosh S. Weavability of Compact yarn. Melliand International. 2003;9:311-314.

4. Celik P, Kadoglu HA. Research on the compact spinning for Long Staple Yarns. Fibers and Textiles in Eastern Europe. 2004;4(48):27-31.

5. Dakin G. Doubled yarns Part IV. The Effect of Twist And Structure on the Physical Properties of Some Manifold Yarns. The Journal of the Textile. 2008;48(7-8):T293-T320.

6. Dash JR, Ishtiaque SM, Alagiurasamy R. Properties and processibility of Compact yarns. Indian J Fiber \& Text Res. 2002;27:362-368.

7. Ghosh A, Ishtiaque SM, RengasamyR S. Analysis of Spun Yarn Failure. Part I: Tensile Failure of Yarns as a Function of Structure and Testing Parameters. Text Res J. 2005;75(10):731-740.

8. Goktepe F, Yilmaz D, Goktepe OA. Comparison of Compact yarn Properties Produced on Different Systems. Text Res J. 2006;76(3):226-234.

9. Grosberg P, Iype C. Yarn Production-Theoretical Aspects. USA: CRC Press; 1999. p. 1-220.

10. Gupta RK, Jivani VM, Patel BM. Effect of Doubling of yarn classimat yarn faults. $J$ Text Association. 1984;45(6):203-205.

11. Hechti R. Compact spinning systems-an opportunity for improving the ring spinning process. Melliand International. 1996;2(1):12-13.

12. Hari PK, Balasubramanian P,sengupta AK, et al. Effect of Doubling on the Tenacity of Rotor-spun yarns. J Textile Institute. 1985;76(5):383-386.

13. Ishtiaque SM, Subramani P, Kumar A, Das BR. Structural and Tensile Properties of Ring and Compact Plied yarns. Indian J Fibre \& Text Res. $2009 ; 34: 213-218$.

14. Ismail MM, Nagarajan P. All about Compact Spinning. The Textile Magazine. 2011;652(6):72-73.

15. Jackowski T, Cyniak D, Czekalski J. Compact Cotton yarn. Fibers and Textiles in Eastern Europe. 2004;12(4):22-26.

16. Kane CD, Patil UJ, Sudhakar P. Studies on the influence of knit structure and stitch length on ring and compact yarn single jersey fabric properties. Text Res J. 2007;77(8):572-582.
17. Kretzschmar SD, Ozguney AT, Ozcelik G, et al. The comparision of cotton knitted fabric properties made of compact and conventional ring yarns Before and After the Dyeing Process. Text Res J. 2007;77(4):233-241.

18. Krifa M, Hequet E, Ethridge D. Compact spinning: New potential for Short Staple Cotons. Textile Topics. 2002;(2):2-8.

19. Lewandowski S, Drobina R, Jozkowicz I. Comparitive analysis of the ring spinning process, both classic and compact-Theoretical Reflections. Part 1: Elaboration of the statistical Model Based on Multiple Regression. Fibres \& Text in Eastern Europe. 2010;(81):20-24.

20. Lin JH, Tsai IS, Hsing WH. Introduction to an Innovative Rotor Twister. $J$ Text Institute. 1998;89(2):266-273.

21. Magel M, Putzger G, Offermann P. Controlling the properties of Folded yarns through the twist structure. Melliand Textilber. 1999;80(5):352-357.

22. Nikolic M, Stjepanovic Z, Lesjak F, et al. Compact Spinning for improved quality of Ring spun yarns. Fibers \& Text in Eastern Europe. 2003;11(4):30-35.

23. Onder E, Kalao F, Ozipek B. Influence of Varying Structural Parameters on the Properties of 50/50 Wool/Polyester Blended Fabrics. Text Res $J$. 2003;73(10):854-860.

24. Ozdil N, Ozdogan E, Demirel A, et al. Comparative study of the characteristics of Compact Yarn-Based Knitted fabrics. Fibers \& Text in Eastern Europe. 2005;13(2):39-43.

25. Parthiban D, Maruthamani M. Effect of Fabric softener on the thermal comfort of cotton and polyester fabrics. $J$ the Text Association. 2006;32(4):446-452.

26. Sharabaty T, Biguenet F, Dupuis D, et al. Investigation on Moisture transport through polyester/cotton fabrics. Indian J Fiber \& Text Res. 2008;33(4):419-421.

27. Stahlecker F. Compact or condensedspinning: a market niche or the summit of ring spinning. Melliand International. 2000;6(1):30-33.

28. Stalder H. New spinning process ComforSpin. Melliand International. 2000;6(2):22-25.

29. Treloar LRG. The geometry of multi-ply yarns. $J$ Textile Institute. 1956;47(6):348-368.

30. Yilmaz D, Usal MR. A comparison of compact-jet, compact, and Conventional ring-spun yarns. Text Res J. 2010;81(5):459-470.

31. Zaghouani F, Hassen MB, Halimi MT, et al. Comparative study of the quality of open-end, ring and hybrid folded yarns of cotton. $J$ Text Institute. 2009;100(3):260-264.

32. Booth JE. Principles of Textile Testing. Delhi: CBS Publishers \& Distributors; 1996. p. 286-287. 